\title{
CSR in Professional Sport: An Examination of Community Models
}

\begin{abstract}
The purpose of this paper is to explore how corporate social responsibility (CSR) is implemented in professional sport, specifically to compare and contrast different organisational structures used in the implementation of CSR. A qualitative case study methodology was adopted, drawing on interviews with key stakeholders of 12 professional sporting organisations and their relevant CSR departments. Secondary sources such as annual reports, newsletters, websites and other organisational documents were also collected and analysed. This research found a variety of challenges and opportunities for employing CSR, including alignment of strategies, conflict of power and access to resources. Discussions explore how communication, collaboration and different governance models can improve the inter-relationship of these entities. This paper offers an empirical identification of critical opportunities and challenges within professional sporting organisations. This paper extends the current research by looking at CSR management and governance, specifically exploring the inter-relationship between professional sporting organisations and their associated foundations.
\end{abstract}




\section{Introduction}

For many years, society has believed that businesses have a responsibility to the communities in which they operate. However we are only now beginning to understand the complexities of this concept known as corporate social responsibility (henceforth CSR) — a broad field that encompasses terms such as sustainability, community engagement and corporate citizenship — that is attracting more attention than ever before, both from an academic and industry perspective. The fundamental principle of CSR is that businesses are responsible for their actions and they therefore should embrace societal concerns into their operations (Porter \& Kramer, 2006). CSR is no longer regarded as an optional extra. Rather, it is reflective of a deeper change in society towards critically evaluating organisations and their relationships to stakeholders (Lewis, 2001). The body of 'good practice' in the field of CSR is gaining momentum and the value of these approaches is becoming more appreciated (Levitt, 2012). Researchers are moving beyond the definition and identification of CSR activities to examine CSR from a more strategic management perspective (Husted \& Salazar, 2006). The research literature currently offers contributions towards CSR theory and concepts that are broadly applicable to a wide range of industries. In practice however CSR differs significantly from one industry to another.

The specific focus of this research is the professional sports industry; sport has great power and influence in Western society, and there is an increasing expectation that this will be utilised in a way that is both economically sound and socially beneficial (Smith \& Westerbeek, 2007). However, many believe that work on the intersection of CSR and sport requires further development (Blumrodt, Bryson, \& Flanagan, 2012; Breitbarth, Hovemann, \&Walzel, 2011). 
With the growth of the sport industry and the ingrained nature of its community engagement practices, professional sport organisations present a rich context in which to study CSR (Babiak \& Wolfe, 2009). Despite the prevalence and magnitude of community engagement and socially responsible activities, little attention has been devoted to understanding the structures, strategies, or benefits derived from them. This research also draws on multiple perspectives but specifically on the internal perspective of the inter-relationship between the two entities whereas previously research has focused on the external relationships (Jenkin \& James, 2012; Kihl, Babiak, \& Tainsky, 2014; Walters \& Panton, 2014). This research also extends existing research by identifying that strategic alignment can act as a critical mediating factor in resolving some of these issues such as power and resource imbalance.

This research presents selected findings from a wider study into corporate social responsibility practices of professional sporting organisations worldwide. The opportunities and challenges of implementing CSR within different structures are explored from an internal management viewpoint. This knowledge will ultimately provide guidance to the management of professional sport organisations in developing effective CSR programs that not only contribute to society but also provide business results.

\section{Corporate Social Responsibility in Sport}

Despite its long history and increasing prominence in business, there has been an expansion of terms and definitions to describe CSR. One common definition states that CSR is "the manner in which businesses manage their economic, social, and environmental impacts and their stakeholder relationships in key areas of influence such as the workplace, the marketplace, 
the supply chain, the community, and public policy realm" (John F. Kennedy School of Government, 2008, p. 1).

Businesses do not function in isolation from the community around them. Success in business, in particular the professional sporting industry, necessitates the ability to work within a complex set of stakeholders, from employees, fans, media, broadcasters, sponsors and the general community in which they operate (Babiak \& Wolfe, 2009). A stakeholder, in this context, refers to 'any group or individual that can affect or is affected by the activities of the corporation' (Freeman, 1984, p. 46). In other words, this approach asserts that management's responsibility is to seek an ideal balance in responding to the diverse needs of all constituents affected by its decisions (Schiebel \& Pöchtrager, 2003). Furthermore, CSR is deemed to be strategic when it yields substantial business-related benefits to the organisation, in particular by supporting core business activities and contributing to the organisation's effectiveness in accomplishing its mission (Burke \& Logsdon, 1996). Across industries, there has been a progressive shift towards societal improvement integrated into economic value creation, otherwise known as shared value (Porter \& Kramer, 2011).

The study of CSR has been widespread in the management and organisational behaviour literature and it has also entered the sport management literature and gained significant attention from researchers over the past ten years (e.g. Babiak \& Wolfe, 2006; Bradish \& Cronin, 2009; Breitbarth \& Harris, 2008; Breitbarth et al., 2015; Smith \& Westerbeek, 2007; Walker \& Kent, 2009; Trendafiova et al., 2017; Zeimers et al., 2017). There is a growing body of literature on CSR in professional sport however despite limited empirical research on the intersection of CSR and sport, the increased focus on community and the rapid engagement into socially responsible 
initiatives indicate that CSR is gaining considerable currency in the professional sport industry (Babiak \& Wolfe, 2006; Breitbarth et al., 2015).

Professional sport organisations have been active in community initiatives for decades, from athletes visiting children in hospitals, to teams running programs that promote healthy lifestyles and participation in physical activity (Extejt, 2004). A variety of elements have led to the growing importance of CSR for PSOs (Lau, Makhanya, \& Trengrouse, 2004; Walker \& Kent, 2009; Breitbarth et al., 2015). For example, the globalisation of professional sport over the past century has meant that teams are now influential members of the global community, becoming big businesses themselves that are noticed and recognised all around the world. Defining organizational governance and outlining differences between corporate and non-for-profit governance, particularly in Australia (Hoye \& Cuskelly, 2007) marked an important advancement for sport governance. With both sport and business concerned with widening market share, increasing profits, and strengthening brand reputation, professional sport is considered a rich context in which to study CSR (Babiak, 2010). Existing research consistently refers to sport as a vehicle for CSR delivery as it offers a bridge between social and economic gaps, an opportunity to improve the quality of life, and a stimulus to partner with large corporates (Smith \& Westerbeek, 2007; Walters, 2009).

\section{CSR Implementation}

Organisations are realising that effective management of their social and environmental risks can improve business performance (Margolis \& Walsh, 2003). There are a variety of structures through which to implement CSR at an organisational level. The focus of this research 
is twofold: corporate foundations and individual business units as entities that employ CSR initiatives.

In recent years, there has been resurgence in the creation of foundations around the world, particularly those established by corporations (Anheier \& Benner, 2003). Charitable foundations have become a popular way in which CSR initiatives are employed on behalf of an organisation. A foundation is a type of non-profit organisation with structural and strategic independence from the associated sporting club (Westhues \& Einwiller, 2006). In the professional sport industry, foundations typically run their community CSR initiatives on behalf of their associated sporting organisation. While the foundations undertake the community work of the sporting organisation (Jenkins \& James, 2011), it is important to note that they are distinctively separate entities.

The other model by which organisations implement and deliver CSR programs is through a specific business unit operating within the organisation (Husted, 2003). In professional sport, this is typically referred to as a 'community department'. It is through this department that CSR initiatives are run within certain PSOs (Jenkins \& James, 2011). A community department is typically a direct business unit within the organisation, just as a marketing or accounts department. It is these two models that are explored within the research.

In the case of foundations and their parent organisations, knowledge management and communication are of particular importance (Westheus \& Einwiller, 2006). It has been previously well established that inter-organisational collaboration and communication networks are becoming increasingly important for organisations (Clegg, Kornberger, \& Pitsis, 2008). There has been a lot of research looking at why different organisations may engage in collaboration with others for reasons such as efficiency necessity, asymmetry, reciprocity, 
efficiency, stability, legitimacy (Oliver, 1990). At the same time, issues of trust, power and resources have also been identified as issues between these organisational entities (Bensimon, 1999).

However, only a small number of recent studies have examined foundations within the professional sports industry. Walters (2009) identified what he called the 'community sports trust model' (i.e. foundation model) as an ideal delivery agent for a commercial organisation to meet their CSR objectives. In a working paper on community initiatives in the UK football industry, Jenkins and James (2011) examined what they called the 'charitable trust model' (i.e. foundation). In their report, they completed a broad investigation into the social and environmental responsibilities of UK Premier League Football Clubs with specific reference to the challenges of undertaking community initiatives from an external perspective (Jenkins \& James, 2011). They identified financial pressures and lack of awareness of the work of community trusts as the main challenges when undertaking community initiatives.

The link between foundations and professional sporting organisations creates a unique dynamic, bringing a variety of stakeholders together in collective forums. The purpose of this research is compare and contrast how CSR is strategically managed in professional sport organisations through two fundamentally different structures, charitable foundations and 'inhouse' community departments. Whilst the importance of CSR has been well researched and written about, the implementation of CSR in sport has not been adequately explored. Further academic work at the intersection between CSR and sport in management is considered essential (Breitbarth et al., 2011). Furthermore, the increasing trend of employing the foundation model has led to a call for more research into this model (Jenkins \& James, 2011; Walters, 2009). It is also relevant to examine the applicability of this phenomenon outside of football in the UK 
(Walters, 2009). Thus, the current research aims to provide insight into, not only the potential opportunities, but also the challenges of the two different structures. It is important that these challenges are recognised and addressed adequately so as to ensure greatest efficiency and success in employing CSR through the chosen model.

\section{Methodology}

As one part of a larger research investigation, this paper reports specifically on different models of CSR implementation in professional sporting organisations. A case study approach was used for this detailed exploration as it is ideal when a holistic, in-depth investigation is required into a contemporary phenomenon within its real-life context (Yin, 2009).

Although qualitative case study methodology is a distinct form of empirical inquiry, it does have some limitations that must be addressed (Saunders, Lewis \& Thornhill, 2009; Walle, 1997). One of the criticisms of case study research is that the method maintains a bias toward verification, understood as a tendency to confirm the researcher's preconceived notions (Flyvberg, 2006). However, case studies have been shown to have their own rigour, albeit different, but no less strict than the rigour of quantitative studies (Campbell, 1975). It is acknowledged that the relatively small sample size of participants may leave the results susceptible. However, the purpose of this study is not to generalise, but rather to establish how PSOs implement and integrate CSR in their particular community models.

According to well-acknowledged recommendations, case selection in the research was based on two factors: feasibility and sample variation in critical categories (i.e. geographical location) (Eisenhardt, 1989; George \& McKeown, 1985; Yin, 2009). This study focused on professional sporting organisations across three distinct geographical areas: Australia, North 
America and the United Kingdom (UK). These three geographical areas were chosen because they represent popular sporting nations with highly established professional sporting leagues. Furthermore, they all represent relatively similar markets in terms of economic development and political freedom (Baugh, Bodie, \& McIntosh, 2007). Within each geographical case, four organisations were selected. Organisations were chosen based on the possibility of gaining access to the required information, the presence of innovative programs and the richness of information on CSR activities A broad range of organisations across several sporting codes were represented in order to extend the current research. The sporting code was not determined to be a significant point of difference, given that the interviews focused on the perspectives of the internal management of the organisations, rather than the sport delivery itself. This is reflective of other research which also investigates CSR management across sporting codes (Babiak \& Wolfe, 2009).

Based on the nature of the cases and the participants involved in this study, the two sources of evidence collected in this study were organisational documentation and interviews. As Yin (2009) identified, obtaining data from more than one source allows for richer data and has the potential to create stronger, more trustworthy findings. No single source has a complete advantage over the others; rather, they can be complementary or used in tandem (Tellis, 1997).

As one of the many qualitative data collection methods, interviewing has been well established to provide the most direct, research-focused interaction between researcher and participant (Kvale, 1996). This qualitative method allows for greater depth and quality of responses than is usually possible in a survey or questionnaire format (Burns, 2000). The participant-selection process of sampling used in this research involved the deliberate selection of individuals within a certain population (Minichiello et al., 1995), primarily on the basis of the 
relevance to the aim of the research. . Feasibility was largely determined by stakeholders' willingness to participate in the study. Sample variation referred to key informants from both the PSO and the associated foundation or community department; 'key informants' are defined as persons that are considered to be influential, prominent and well informed in their respective organisation (McMillan \& Schumacher, 2001, p. 427). Thus, the targeted participants were selected because they were directors, heads of departments, or senior executives that were directly responsible for CSR activities and strategies.

Interview data was collected across 2012 and 2013, with a total of 22 executives and managers interviewed; nine were female, thirteen were male. Thirteen participants represented the PSO side and nine were from associated PSO foundations. This gave a balanced view from both sides. Interviews with each of the participants were conducted according to an interview guide. The interviews sought the specific, subjective perspectives of those directly involved in the organisations and its CSR implementation. Participants were asked a variety of open-ended, in-depth questions regarding their organisation's CSR practices and strategies in the context of the individual organisation. Each interview began with fundamental demographics including size of employee and fan base and other key stakeholders of the organization. Specific questions followed investigating which from a governance and strategic perspective, which department(s) influenced key organizational decision on CSR and how the CSR strategy was determined. Implementation related questions covered priorities and goals of the CSR programs and initiatives, unique and differentiating factors, key partners in CSR implementation and relevant challenges faced. A further 12 follow-up interviews were conducted as a means of following up on certain discussions with available participants from each organisation. Interviews continued until they reached saturation, that is, no extra questions yielded additional insights (Strauss \& 
Corbin, 1998). A total of 34 interviews were conducted across the participants. All interviews were recorded and transcribed verbatim.

In addition to the interviews outlined above, organisational and archival documents were also collected as additional sources of data. Documents include material from an array of authors: governments, organisations, media and individuals. In terms of documentary sources, the study targeted particular types of material categorically organised as 'internally produced' (managerial) documents and 'externally produced' (journalistic) documents. Managerial documents refer to those produced by the PSOs or associated leagues. This included publicly available texts such as mission and vision statements, annual reports, policy documents, newsletters and any other correspondence that related to the CSR activities or strategies of these organisations. These documents provided insight into how the organisation perceived and portrayed its CSR. Journalistic documents refer to those that were produced by external sources such as the local, national or international media (i.e. newspapers and magazine articles) and were collected as they provide critical insight from the public's perspective.

Document collection for each PSO began in January 2012 and continued over the course of two and a half years until July 2014. A total of 521 documents and records were collected and subsequently collated and coded in $\mathrm{NVivo}^{\mathrm{TM}}$. These materials included a range of annual reports, CSR policies, newsletters, webpages, and other relevant organisational documents. The internal documents were acquired either from the organisations' websites or provided by the participants on the day of the interview. Interview transcriptions and organisational documents were reviewed and a directed content analysis of the qualitative data was conducted (Hsieh \& Shannon, 2005). 
Analysis of the data was conducted according to Strauss and Corbin's (1998) three levels of coding: open coding, axial coding and selective coding. Open coding was undertaken through a line-by-line analysis, a form of coding which involves close examination of data, phrase by phrase and sometimes word by word. Coding was also conducted by analysing whole sentences or paragraphs. Axial coding was used to identify links and relationships among emerging categories. Selective coding was then used to piece together and connect the relationships in meaningful, coherent ways. Once a finalised list of codes and broad themes were developed, the textual data was analysed again with the revised codes. In some specific cases, word frequency searches were employed to determine the popularity of certain themes across different categories (i.e. geographic regions). Throughout the data analysis process, memos and notes were made using $\mathrm{NVivo}^{\mathrm{TM}}$ to ensure a degree of reflexivity related to the data and a system by which questions or issues associated with the data were noted (Oliver, Serovich, \& Mason, 2005). Once a finalised list of codes and broad themes was developed, textual data was analysed again with the revised codes. This process continued with extensive checking and recording.

\section{Results}

Across the organisations involved in this research, two general models were explored: community departments and foundations. In the sample of 12 PSOs, four had community departments within the club; the other eight followed the foundation model. Both models had similar functions, with the overall objective of running CSR initiatives and programs. The results revealed significant opportunities and challenges between different structures for the implementation of CSR initiatives. 
This research fundamentally focused on the working relationship between the PSO and their associated foundation. The examination of community departments served as a critical comparison to the foundation model. The findings of this research identified three management and governance related elements including (1) alignment of strategies, (2) conflict and (3) access to resources. These critical features created both challenges and opportunities, as outlined below.

\section{Strategic Alignment}

Strategic alignment refers to the process and result of linking an organisation's structure and resources with its strategy and business environment (Morrison et al., 2011). In this research, this is extended to the strategic alignment between multiple entities (i.e. between the PSO and the foundation). Aligning an organisation's strategies, processes and people is challenging in most circumstances. Moreover, when a PSO has two distinctly separate but overlapping entities, aligning strategies between the two proved to be even more difficult. As one executive from the foundation side explained:

From a strategic standpoint, there's been a lot of work put into making sure the two organisations are separated ... But I'd say maybe the pendulum is swinging back a little bit in that the club and the foundation are starting to realise that if you help sell the brand, then we can help have better impact and reach more people. (Respondent B2)

Ideally, organisations work towards a clear coherent alignment between the mission of the foundation and the business plan of the PSO. However, as one respondent elaborated, this takes a lot of coordination to execute: 
In terms of our [Foundation's] strategies, we have to work hand-in hand to make sure that our strategies align ... so that [the club's] commercial strategies link with my [Foundation's] commercial team ... It's a massive relationship.

The reality exists that while they have their own separate business partners, many foundations and PSOs are deeply embedded with each other's strategies and business plans. Many respondents specifically acknowledged the difficulty of maintaining strategic alignment and balance with their counterpart internally, while also not competing against each other in the external market. As one respondent explained:

On our side [at the Foundation], our challenge is trying not to compete for the same external dollar. So we are always trying to find that balance for the bottom line for the club ... enhancing what the club does through charitable initiatives. It is a balancing act. (Respondent C2)

In one case, the foundation was restricted by their PSO from acquiring corporate partners. Specifically, they were not permitted to work with any corporation that was not already a corporate partner of the PSO entity. The justification for this was that the PSO did not want to allow an external corporation to associate with the high-profile brand through the sponsorship of the foundation, for a considerably smaller amount of money than that what would be required to gain sponsorship with the PSO.

That being said, a few respondents did consider their foundation and clubs to have well aligned strategies and saw this as advantageous for both entities. These respondents considered the foundation to be representative of the PSO within the community, specifying that business objectives overlap between the two entities. These business objectives include being more visible 
in the community, trying to encourage more support and helping to strengthen communities through the use of sport and health and wellness. One respondent explained how they work together with their associated PSO:

We work together in terms of ... basically we represent the football club in the communities, because we are able to interact with the kids. We are using their brand but we are also doing it with our own business objectives. (Respondent H1)

One important aspect of this alignment and success was collaboration. In its simplest form, collaboration is a type of a cooperative relationship in which people are "working across organisational boundaries towards some positive end" (Huxham \& Vangen, 2005, p. 4). As one participant from the foundation side explained: "We are here to support our mission but also to mesh seamlessly with [the PSO] ... It's been much easier since we started to collaborate" (Participant C2). Collaboration involves a wide and sometimes complex range of stakeholders working together to achieve a synergistic outcome towards shared value.

In comparison, strategic alignment and collaboration was not raised as an issue within organisations that employed community departments to run their CSR programs. One interviewee explained that they "all work under one roof and work under the same overarching strategy for the club" (Participant G1). In part, this could be due to the fact that interorganisational boundaries do not need to be passed in these cases.

\section{Conflict}

Another challenge of the inter-relationship between the foundations and PSOs mentioned by the respondents was the power struggle between these two entities. Interviewees from the 
foundation side explained that they felt they had significant day to day responsibility and accountability to the PSO but very limited power or influence in making decisions. As one respondent explained:

So I sit here as CEO of the Foundation knowing I have all the responsibility of making this work. But I don't have as much power as I have responsibility. Because ultimately, I need a phone call from over there [PSO head office] to say "you're doing that ... or you're not doing that". (Respondent I1).

This issue of power and responsibility was reiterated by many participants and clearly highlights the conflict and tension that exists between foundations and PSOs. Some executives from the foundation side felt that they were not being valued for the business benefits they provided to the PSO and emphasised the need for the PSO to reframe the foundation as an asset. For example, one manager highlighted, "getting better integration with the club ... that's our biggest challenge right now. One thing that is holding that up is the relationship with the club ... until they start viewing us as an asset" (Participant B1). Interestingly, this tension was not mentioned by executives from the PSO side, reflecting a divide in understandings and perceptions.

On the other hand, respondents from PSOs that had community departments did not raise any concerns on this issue. By nature of their structure, community departments did not experience the same power struggle as the foundation. As a department within the PSO, the dynamics are very different than that of a foundation which runs independent yet by the side of the PSO.

\section{Access to Resources}


Another difference between foundations and community departments revealed through the research was access to resources. These resources are primarily financial, such as government funding and corporate partnerships. Participants from community departments discussed challenges in securing external funding for projects. One participant explained: "Governments do not want to fund a program within a club that is perceived by the public to be making millions of dollars each year" (Participant F2). From this perspective, the foundation model allowed for better access to external resources to employ CSR initiatives.

Many participants from the foundation side mentioned the relationship with their PSO regarding access to resources. In some cases, the PSO acted as a primary donor of money and inkind resources for their associated foundation. However, in other cases the foundation did not receive substantial resources or funding from the PSO. This was not seen as a negative. Rather, foundations saw this as part of the goal towards being more sustainable and independent from their PSO. As one senior executive articulated:

The football club provides about $10 \%$ of our funding coming in ... we are looking to get to $0 \%$. We want to be sustainable. We can use the [Club's] donations to get the programs off the ground and pilot projects and secure that evidence. (Respondent J2)

Foundation representatives recognised that PSO funding was a significant support and benefit. Funding from the PSO, in some cases, was used to get new programs started, or, in others as a support in case funding from external sources ceased. However, all participants from the foundation side emphasised the desire to become sustainable and financially independent from the PSO. Once foundations become more established and have, as one participant called it 
"some runs on the board" (Participant F2), they are better able to secure funding from outside sources such as government funding, philanthropic donations and corporate investment. Results indicate that in a foundation's first years, the PSO is often committed to underwriting their foundation's programs.

The findings revealed that access to funding and resources had interesting dynamic differences between the foundation and community department models of CSR implementation. The foundation model allowed for, and encouraged, financial sustainability and autonomy for the foundations from their PSO. On the other hand, the community departments, by their very model, receive direct funding from the PSO and therefore will never be completely autonomous. In bidding for external resources, foundations are arguably at an advantage because they are seen to be separate from the PSO and have a clearly defined mission. As a community department, there is thought to be a perception that that money would be going to the club, rather than the community. The perceived wealth of a PSO was considered to have a potential negative effect on securing external funding from the government, for example.

In summary, there are two main governance models for the implementation of CSR, foundations and community departments. Foundations are becoming increasingly common, with all North American and UK PSOs involved in this study employing this model. There appears from the data to be a number of advantages and disadvantages of the foundation model with respect to how CSR is acted upon at the PSO level. Overall, it is clear that a balancing act is critical to ensure that the difficulties associated with this method of delivering CSR do not outweigh the benefits of such a model.

\section{Discussion}


It has been well documented that many of professional teams in the North American context (Babiak \& Wolfe, 2009), in UK football (Anagnostopoulos, 2013; Bingham \& Walters, 2013) and in European football (Kolyperas \& Sparks, 2011; Walters \& Tacon, 2011) have progressively established charitable foundations for delivering their CSR-related agendas. This research reflected a similar shift in North American and UK contexts. However, none of the Australian-based PSOs involved in this research had separate foundations. This reflects an interesting geographical difference in the governance and strategy of North American and UK CSR.

The findings also reveal several critical factors in the complexities of the relationship between PSOs and their associated foundations. Results highlight the balancing act between PSOs and their foundations across the identified elements such as strategic alignment, conflict of power and access to resources. These variables align and support existing collaborative governance research (Ansell \& Gash, 2008; Bensimon, 1999; Oliver, 1990). This research extends the above studies by identifying that strategic alignment can act as a critical mediating factor in resolving some of these issues such as power and resource imbalance.

It has previously been asserted that all community departments, regardless of department foundation structure, function in similar ways (Jenkins \& James, 2012). However, the current study presents different findings. Foundations and community departments differ significantly, especially in their relationship with their PSO. Interestingly, this contradicts Jenkins and James (2012) assertion that all CSR implementation structures, regardless of department or foundation structure, function in similar ways. The difference in these results is attributed to the perspective from which the results are derived. From a theoretical standpoint, this research draws upon multiple perspectives, highlighting the internal perspective of the inter-relationship between the 
two entities building upon previous research that focused primarily on the external relationships (Jenkin \& James, 2012; Kihl, Babiak, \& Tainsky, 2014; Walters \& Panton, 2014). This research also extends existing research by identifying that strategic alignment can act as a critical mediating factor in resolving some of these issues such as power and resource imbalance.

One important dynamic of the relationship between PSOs and their foundations, identified in this research is autonomy. Foundations strived for autonomy especially with regards to financial support and sustainability. The findings suggests that foundations may be, from one perspective, an advantageous model because funders can clearly see that their money is going to the community rather than directly to the PSO. This was described by several participants with respect to securing external funding for the foundation. Previous research also describes autonomy and transparency as an advantage of the model in that there is less conflict with the demands of a football club at an operational level (Jenkins \& James, 2012).

The findings in this study indicate, however, that this autonomy can also cause issues such as misalignment of strategies. In some environments, autonomy may isolate the minority and alienate different groups, which could eventually lead to segregation between the two entities (Suksi, 1998). Originally proposed in the context of ethnic-political conflict (Suksi, 1998), this concept can be applied to inform the dynamic between foundations and PSOs. Increased autonomy can make the group feel isolated, rather than empowered. That being said, it is important to note that autonomy can also be a method of relieving tensions (Suksi, 1998) and should be further explored and applied for corporate foundations.

In attempting to understand the dynamic between foundations and PSOs, a focus on personal relations and power is informative. The quality of the personal and professional 
relationships between the foundation and the PSO executives and staff play a substantial role in the management of CSR. Power has been argued to be a characteristic of human relating such that it is a pattern of interaction rather than an object or a thing that can be possessed (Dobson \& Sinnamon, 2001; Newton, 1998). Thus, the interaction between the foundations and PSOs is critical, particularly in this study, through communication and collaboration.

In the case of foundations and their parent organisations, knowledge management and communication are of particular importance (Westhues \& Einwiller, 2006). This was evident throughout the research results. On one hand, in the cases of foundations, the sentiment expressed was that communication between the club and the foundation can be challenging. One reason for this, as identified above, is a difference in agenda and strategic objectives. On the other hand, community departments within the PSO were found to have better communication with their counterparts. Extending the previous findings that identify communication as a difficulty for CSR implementation in professional sport (Jenkins \& James, 2012; Walker, 2009), this research specifies that the communication challenges and opportunities differ significantly depending on the governance models in place.

It was also evident in the research findings that inter-organisational collaboration and communication networks have become increasingly important for PSOs and their foundations or community departments, which supports and applies Clegg et al.'s (2008) research in the context of CSR and professional sport. In regards to elements of collaboration as outlined by Oliver (1990), this research revealed that foundations and PSOs collaborate for reasons of reciprocity and efficiency. Reciprocity dictates that the interest of both organisations might be better pursued when they join forces and form an alliance from which both benefit (Oliver, 1990). The motivation behind efficiency is to improve organisational performance through collaboration and 
communication (Clegg et al., 2008). Not only are the PSO and the foundations or community departments usually working under the same brand name, they may also share a variety of other assets (e.g. corporate partners). This research showed that when organisations communicate and collaborate through strong strategic alignment, objectives are more effectively achieved.

The strongest structural link between the foundation and the PSO is in the composition of the board. It has been well established that boards are critical in shaping and overseeing active engagement and strategic direction around CSR policies and long-term value creation (Cramer \& Hirschland, 2006; Kiel \& Nicholson, 2003; Schacter, 2005). There is a growing recognition that the CSR agenda will increasingly overlap with the corporate governance agenda, highlighting the fact that boards are critical to the transition and thinking around CSR and sustainability (Ingley, 2008). This was demonstrated in the current research study within a professional sport management context.

Specifically in this study, the board was considered to be an important communication channel between the two entities, the foundation and the PSO. In order to improve face-to-face communication, the findings suggest that organisations should include a representative from the founding corporation who is responsible for the CSR strategy on the foundation's board. The same can also be said vice versa, such that the foundation's representative must sit on the founding PSO's board. This structural link enables the foundation to remain closely linked and integrated with the PSO, therefore enabling and enhancing communication and collaboration channels. This research also highlights the importance of developing inclusive forms of stakeholder dialogues, including boards across foundations and the PSOs, to improve CSR performance and enhance shared value integration. In this way, boards and corporate governance becomes a critical feature of CSR implementation and represents an area for future research. 
Fundamentally, the potential risks and rewards of CSR create requirements for new forms of governance, as they relate to strategies which determine the sharing of responsibilities and the appropriate allocation of power in these structures (Bressers \& Rossenbaum, 2003; Clarke, 2004). As evidenced in this empirical research, governance involves not only transparency and accountability but also collaboration and communication between stakeholders (Clarke, 2004). Furthermore, governance in the inter-organisational domain, in this case between foundations and PSOs, must deal with the complex interdependencies between the people involved (Bertels \& Vrendenburg, 2004).

Whilst beyond the scope of this study another approach that should be considered for future research involves the deeper analysis of the rivalry that develops between twin (parent and sibling) organizations. A psychodynamic approach to analysing this type of 'twin' organizational relationship may prove beneficial. As suggested by the work of Stein $(2014$, p. 187) "the rivalry that ordinarily exists between organizations will be much strengthened in the case of twin organizations, because they invariably reference themselves in relation to each other."

As mentioned above, the findings highlighted communication and collaboration as critical features in the relationship between PSOs and their CSR structure, whether that is through a foundation or a community department. If the work of the foundation is wellcoordinated with that of the founding organisation and knowledge is transferred smoothly between these organisational entities, the PSO can benefit from the foundation's activities and insights. However, foundations by their legal nature are independent bodies that exclusively pursue public-benefit purposes (Westhues \& Einwiller, 2006). Thus, this relationship is not free of conflicts, as alluded to in the above discussion on autonomy. While foundations are structurally and strategically separate from the PSO, it is important that they maintain a direct 
association through collaboration and communication. This requires a coordinated and integrated effort across many aspects of governance and management, from policies and strategy to the economic, social and environmental dimensions (Berger \& Steurer, 2009). It is this balance of reliance, support and autonomy that makes CSR management unique in professional sport.

\section{Conclusion}

Overall, this research explored the opportunities and challenges for two models of implementing CSR in professional sport. Foundations typically run all of the community and social-based initiatives on behalf of their associated sporting organisation. The other model by which organisations implement and deliver CSR programs as seen in this research, is through a department or business unit within the organisation. Whilst the foundation model may enable better access to external resources than that of community departments, there are other challenges such as conflict of power and strategic alignment that were identified. With the increasing trend of PSOs adopting the foundation model, this research provides practical insights into the challenges and opportunities of that structural change. Future research into different sporting and international CSR contexts will help embed the current work into a broader understanding of how CSR can be employed in sports management. Further research is also planned to examine how these structures impact on CSR outcomes of the organisation.

The contribution of this research is the identification of the advantages and challenges of the two main CSR structures within PSOs. This research extends the current research by looking at CSR management from an internal management perspective, specifically looking at the relationship between the PSO and its foundation. A balancing act is critical to ensure that the difficulties associated with this method of delivering CSR do not outweigh the benefits of such a 
model. By improving the implementation of CSR initiatives, professional sport organisations may experience increased strategic beneficial impact for both the organisation themselves and the communities in which they operate.

\section{References}

Anheier, H.K., \& Benner, A. (2013). The study of the nonprofit enterprise:Theories and Approaches, New York: Plenum Kluwer.

Ansell, C., \& Gash, A. (2008). Collaborative governance in theory and practice. Journal of Public Administration Research and Theory, 18, 543-571.

Babiak, K. (2010). The role and relevance of corporate social responsibility in sport: A view from the top. Journal of Management \& Organization, 16, 528-549.

Babiak, K., \& Wolfe, R. (2006). More than just a game? Corporate social responsibility and Super Bowl XL. Sport Marketing Quarterly, 15, 214-222.

Babiak, K., \& Wolfe, R. (2009). Determinants of corporate social responsibility in professional sport: Internal and external factors. Journal of Sport Management, 23, 717-742.

Bartee, H. (2005). The role of antitrust laws in the professional sports industry from a financial perspective. The Sport Journal, 8.

Baughn, C.C., Bodie, N.L., \& McIntosh, J.C. (2007). Corporate social and environmental responsibility in Asian countries and other geographical regions. Corporate Social Responsibility and Environmental Management, 14, 189-205.

Bensimon, S. (1999). Strategic alliance. Executive Excellence, 16, 9. 
Blumrodt, J., Bryson, D., \& Flanagan, J. (2012). European football teams' CSR engagement impacts on customer-based brand equity. Journal of Consumer Marketing, 29, 482-493.

Bradish, C., \& Cronin, J. J. (2009). Corporate social responsibility in sport. Journal of Sport Management, 23, 691-697.

Breitbarth, T., \& Harris, P. (2008). The role of corporate social responsibility in the football business: Towards the development of a conceptual model. European Sport Management Quarterly, 8, 179-206.

Breitbarth, T., Hovemann, G., \& Walzel, S. (2011). Scoring strategy goals: Measuring corporate social responsibility in professional European football. Thunderbird International Business Review, 53, 721-737.

Breitbarth, T., Walzel, S., Anagnostopoulos, C., \& van Eekeren, F. (2015). Corporate social responsibility and governance in sport: “Oh, the things you can find, if you don't stay behind!". Corporate Governance, 15, 254-273.

Burke, L., \& Logsdon, J. M. (1996). How corporate social responsibility pays off. Long Range Planning, 29, 495-502.

Burns, R.B. (2000). Introduction to research methods (4th ed.). London: Sage Publications.

Campbell, D.T. (1975). III. "Degrees of freedom” and the case study. Compartive Political Studies, 8, 178-193.

Clarke, T. (2007). International corporate governance: A comparative approach. New York: Routledge.

Clegg, S., Kornberger, M., \& Pitsis, T. (2008). Managing and organisations: An introduction to theory and practice. Los Angeles, CA: Sage Publications. 
Commission of the European Communities (2001). Green paper - promoting a European framework for corporate social responsibility (Working Paper No. 0366). Brussels: COM.

Cornforth, C. (2005). The governance of public and non-profit organisations. London: Routledge Taylor \& Francis Group.

Cramer, A., \& Hirschland, M. (2006). The socially responsible board. The Corporate Board, 161, 20-24.

Dobson, N., \& Sinnamon, R. (2001). A critical analysis of the organisation of major sports events. In C. Gratton, \& I. Henry (Eds.), Sport and city. London: Routledge.

Eisenhardt, K.M. (1989). Building theories for case study research. Academy of Managemet Review, 14, 532-550.

Extejt, M. (2004). Philanthropy and professional sport teams. International Journal of Sport Management, 5, 215-228.

Flyvberg, B. (2006). Five misunderstandings about case-study research. Qualitative Inquiry, 12, 219-245.

Friedman, A., \& Miles, S. (2006). Stakeholders: Theory and practice. New York: Oxford University Press.

Friedman, M. (1962). Capitalism and freedom. Chicago: Unviersity Free Press.

Friedman, M. (1970, September 13). The social responsibility of business is to increase its profits, The New York Times.

Garriga, E., \& Melé, D. (2004). Corporate social responsibility theories: Mapping the territory. Journal of Business Ethics, 53, 51-71.

George, A.L., \& McKeown, T.J. (1985). Case studies and theories of organizational decision making. Advances in Information Processing in Organizations, 2, 21-58. 
Hoye, R., \& Cuskelly, G. (2007). Sport Governance. Oxford: Elsevier.

Hsieh, H. F., \& Shannon, S. E. (2005). Three approaches to qualitative content analysis. Qualitative Health Research, 15, 1277-1288.

Husted, B. W. (2003). Governance choices for corporate social responsibility: To contribute, collaborate or internalize? Long Range Planning, 36, 481-498.

Husted, B. W., \& Salazar, J. (2006), Taking Friedman seriously: Maximizing profits and social performance. Journal of Management Studies, 43, 75-91.

Huxham, C. \& Vangen, S. (2005). Managing to collaborate: The theory and practice of collaborative advantage. Routledge, London.

Jenkins, H. (2012). CSR in sport: Investigating environmental sustainability in UK Premier league Football Clubs (Working Paper No. 68). Cardiff, UK: The ESRC Centre for Business Relationships, Accountability, Sustainability \& Society at Cardiff Unviersity.

Jenkins, H., \& James, L. (2011). Its not just a game: Community work in the UK football industry and approaches to corporate social responsibility. Cardiff: The ESRC Centre for Business Relationships, Accountability, Sustainability, and Society at Cardiff University.

John F. Kennedy School of Government (2008). CSR initiative. Retrieved June 6, 2016, from http//www.ksg.harvard.edu/cbg/CSRO/home.htm

Keasey, K., Thompson, S., \& Wright, M. (1997). The corporate governance problem - compete diagnoses and solutions. In K. Keasey, S. Thompson, M. Wright (Eds.) Corporate governance: Economic and financial issues (pp. 1-17). Oxford: Oxford University Press.

Kiel, G., \& Nicholson, G. (2003) Boards that work: a new guide for directors. Sydney: McGraw-Hill. 
Kihl, L., Babiak, K., \& Tainsky, S. (2014). Evaluating the implementation of a professional sport team's corporate community involvement initiative. Journal of Sport Management, 28, 324-337.

Kolyperas, D., \& Sparks, L. (2011). Corporate social responsibility (CSR) communications in the G-25 football clubs. International Journal of Sport Management and Marketing, 10, 83-103.

Kurucz, E., Colbert, B., \& Wheeler, D. (2008). The business case for corporate social responsibility. In A. Crane, A. McWilliams, D. Matten, J. Moon, \& D. Siegel (Eds.), The Oxford handbook of corporate social responsibility (pp. 83-112). Oxford: Oxford University Press.

Kvale, S. (1996). Interviews: an introduction to qualitative research interviewing. Thousand Oaks, CA: Sage Publications.

Lau, N., Makhanya, K., \& Trengrouse, P. (2004). The corporate social responsibility of sport organizations: the case of FIFA. Switzerland: International Center for Sports Studies.

Levitt, T. (2012). Partners for good: Business, government and thethird sector. Surrey, UK: Gower Publishing Limited.

Lewis, S. (2001). Measuring corporate reputation. Corporate Communications: An International Journal, 6(1), 31-35.

Margolis, J. D., \& Walsh, J. P. (2003). Misery loves companies: Rethinking social initiatives by business. Administrative Science Quarterly, 48(2), 268-305.

McMillan, J.H., \& Schumacher, S. (2001). Research in education: a conceptual introduction. (5th ed.). New York: Longman.

Melé, D. (2006). Proceedings from 6th International Symposium on Catholic Social Thought and Management Education, Rome. 
Miles, M. B., \& Huberman, A. M. (1994). Qualitative data analysis: An expanded sourcebook (2nd ed.). Thousand Oaks, CA: Sage Publications Inc.

Minichiello, V., Aroni, R., Timewell, E., \& Alexander, L. (1995). In-depth interviewing: principles, techniques, analysis, (2nd ed.). Melbourne; Longman.

Morrison, E. D., Ghose, A. K., Dam, H. K., Hinge, K. G., \& Hoesch-Klohe, J. (2011). Proceedings from 7th International Workshop on Engineering Service-Oriented Applications, Paphos, Cyprus.

Newton, T. (1998). Theorizing subjectivity in organizations: The failure of Foucauldian studies? Organization Studies, 19, 415-448.

Oliver, D. G., Serovich, J. M., \& Mason, T. L. (2005). Constraints and opportunities with interview transcription: Towards reflection in qualitative research. Social Forces, 84(2).

Plunkett Research (2011). Sports industry overview. Retrieved July 29, 2016 from http://www.plunkettresearch.com/sports-recreation-leisure-market-research/industrystatistics.

Porter, M. E., \& Kramer, M. R. (2002). The competitive advantage of corporate philanthropy. Harvard Business Review, 80(12), 56-72.

Porter, M. E., \& Kramer, M. R. (2006). Strategy and society: The link between competitive advantage and corporate social repsonsibility. Harvard Business Review, 84(12), 78-92.

Porter, M. E., \& Kramer, M. R. (2011). Creating shared value: How to reinvent capitalism and unleash a wave of innovation and growth. Harvard Business Review, 63-77.

Saunders, M., Lewis, P., \& Thornhill, A. (2009). Research methods for business students. London: Pearson Education.

Schacter, M. (2005, May). Boards face new social responsibility. CA Magazine, p. 12. 
Schiebel, W., \& Pöchtrager, S. (2003). Corporate ethics as a factor for success: The measurement instrument of the University of Agricultural Sciences. Supply Chain Management: An International Journal, 8(2), 116-121.

Smith, A., \& Westerbeek, H. M. (2007). Sport as a vehicle for deploying corporate social responsibility. Journal of Corporate Citizenship, 25, 43-54.

Stein, M. (2014). Double trouble: Sibling rivalvry and twin organizations in the 2008 credit crisis. British Journal of Managemetnt.

Strauss, A., \& Corbin, J. (1998). Basics of qualitative research: Techniques and procedures for developing grounded theory (2nd ed.). Thousand Oaks, CA: Sage Publications Inc.

Tellis, W. (1997). Application of a case study methodology. The Qualitative Report, 3.

Trendafiova, S., Ziakas, V., \& Sparvero, E. (2017). Linking corporate social responsibility in sport with community development. Sport in Society, 20, 938-956.

Walker, M., \& Kent, A. (2009). Do fans care? Assessing the influence of corporate social responsibility on consumer attitudes in the sport industry. Journal of Sport Management, 23(6), 743-769.

Wallace, C. (2004). An insider's look at - and love for - pro basketball. In M. Falls (Ed.), Inside the minds: The business of sports, Boston, MA: Aspatore Inc.

Walters, G. (2009). Corporate social responsibility through sport: the community sports trust model as a CSR delivery agency. Journal of Corporate Citizenship, 35, 81-94.

Walters, G., \& Panton, M. (2014). Corporate social responsibility and social partnerships in professional football. Soccer \& Society, 15, 828-846.

Werther, W. B., \& Chandler, D. (2011). Strategic corporate social responsibility: Stakeholders in a global environment (2nd ed.). Thousand Oaks, CA: Sage Publications. 
Westhues, M., \& Einwiller, S. (2006). “Corporate foundations: Their role for corporate social responsibility", Corporate Reputation Review, 9(2), 144-153.

Yin, R. K. (2009). Case study research: Design and methods (4th ed.). Thousand Oaks, CA: Sage Publications.

Zeimers, G., Anagnostopoulos ,C., Zintz, T., \& Willem, A. (2017). Teaming-up for social responsibility programs: The case of Beglian nonprofit sport organizations. Paper presented at the meeting of North American Society for Sport Management, Denver. 